\title{
Effect of HIFU on endometrial receptivity and sex hormone level in uterine fibroid patients and analysis of influencing factors for its treatment rate
}

\author{
YONGMEI CUI $^{1}$, YANYAN DONG ${ }^{2}$, BINGCHENG GUO $^{3}$, CUIHONG XING $^{4}$, \\ XIAOHUI GAO ${ }^{4}$ and DEXING $\mathrm{SU}^{5}$
${ }^{1}$ Department of Ultrasonography, Jining Maternal and Child Health Family Planning Service Center, Jining, Shandong 272000; ${ }^{2}$ Department of Ultrasonography, Jiaxiang People's Hospital, Jining, Shandong 272400; ${ }^{3}$ Department of Ultrasonography, Jining No. 1 People's Hospital, Jining, Shandong 272011; Departments of ${ }^{4}$ Internal Medicine Ward and ${ }^{5}$ Cardiology, Zhangqiu People's Hospital, Jinan, Shandong 250200, P.R. China

Received June 20, 2018; Accepted January 3, 2019

DOI: $10.3892 /$ etm.2019.7194

\begin{abstract}
Effect of high intensity focused ultrasound (HIFU) uterine fibroid ablation on the endometrial receptivity and sex hormone level in uterine fibroid patients and the influencing factors for treatment rate were investigated. A retrospective analysis of 266 uterine fibroid patients admitted to the Department of Gynaecology in the Jining Maternity and Child Care Hospital from October 2013 to October 2016 was performed. Among them, observation group was treated with HIFU ablation $(n=143)$, control group with myomectomy $(n=123)$. The pulsatility index (PI) and the resistance index (RI) of the uterine arterial blood flow were measured during the luteal phase of menstruation by transvaginal ultrasonography. The serum luteinizing hormone ( $\mathrm{LH})$, follicle stimulating hormone $(\mathrm{FSH})$ and estradiol $\left(\mathrm{E}_{2}\right)$ were detected by chemical immunofluorescence. The relationship between HIFU treatment rate and clinical pathology of uterine fibroid patients was analyzed, and univariate/multivariate regression analysis was used to analyze the influencing factors for HIFU treatment rate. There was no significant difference in preoperative and postoperative PI and RI between the two groups $(\mathrm{P}>0.05)$; no significant difference between preoperative and postoperative PI/RI in the same group $(\mathrm{P}>0.05)$. There was no significant difference in preoperative and postoperative $\mathrm{LH}, \mathrm{FSH}$ and $\mathrm{E}_{2}$ between the two groups
\end{abstract}

Correspondence to: Dr Bingcheng Guo, Department of Ultrasonography, Jining No. 1 People's Hospital, 6 Jiankang Road, Jining, Shandong 272011, P.R. China

E-mail: ff090v@163.com

Key words: high intensity focused ultrasound, uterine fibroid, endometrial receptivity, sex hormone level, treatment rate, influencing factor
( $\mathrm{P}>0.05)$; no significant difference between preoperative $\mathrm{LH}$ and postoperative $\mathrm{LH}$ in the same group $(\mathrm{P}>0.05)$, neither FSH or $\mathrm{E}_{2}(\mathrm{P}>0.05)$. Results of multivariate analysis showed that fibroid location and ultrasound contrast intensity were independent influencing factors for HIFU treatment rate $(\mathrm{P}<0.05)$. Treatment of uterine fibroid with HIFU has no effect on the patient's endometrial receptivity and sex hormone level. Fibroid location and ultrasound contrast intensity are independent risk factors for HIFU treatment rate. This study provides guidance for the clinical optimization of treatment methods and is more conducive to the promotion of HIFU ablation therapy.

\section{Introduction}

Uterine fibroid is a common gynecological benign tumor, in which the age of most patients is more than 35 years (1). According to reports in the literature, uterine fibroid can cause increased menstrual blood volume, prolonged menstruation, pelvic distention, soreness of waist or even infertility, due to differences in the size and location of fibroid, severely affecting the quality of lives $(2,3)$. With the development of society, more attention has been paid by women to the quality of life, physical integrity, uterine physiological function and abdominal beauty (4). According to reports in the literature, the endometrial receptivity can be evaluated by a good congestive state of endometrium that is the basic condition for embryo implantation and reflects the capacity of an embryo to be accepted (5). The indicator for assessing the congestive state of endometrium is usually the uterine arterial blood flow parameter, mainly pulsatility index (PI) and resistance index (RI), and the smaller the value is, the more favorable the embryo implantation is (6). Testing the function of sex hormone to assess ovarian can indirectly reflect the health of the uterus. Sex hormone mainly includes follicle stimulating hormone (FSH), luteinizing hormone $(\mathrm{LH})$ and estradiol $\left(\mathrm{E}_{2}\right)$. When ovarian failure occurs, concentrations of FSH and LH will increase (7). Therefore, the clinical use of minimally invasive 
Table I. General information (n, \%).

\begin{tabular}{|c|c|c|c|c|}
\hline \multirow[b]{2}{*}{ Factors } & \multicolumn{2}{|c|}{ Groups } & \multirow[b]{2}{*}{$t / \chi^{2}$} & \multirow[b]{2}{*}{ P-value } \\
\hline & Observation & Control & & \\
\hline Age (years) & $36.25 \pm 7.13(n=143)$ & $35.75 \pm 6.42(n=123)$ & 0.597 & 0.551 \\
\hline Tumor diameter $(\mathrm{cm})$ & $(n=163)$ & $(n=140)$ & 0.212 & 0.729 \\
\hline$<4$ & $80(49.08)$ & $65(46.43)$ & & \\
\hline$\geq 4$ & $83(50.92)$ & $75(53.57)$ & & \\
\hline Tumor volume $\left(\mathrm{cm}^{3}\right)$ & $(n=163)$ & $(\mathrm{n}=140)$ & 0.196 & 0.730 \\
\hline$<54$ & $81(49.69)$ & $66(47.14)$ & & \\
\hline$\geq 54$ & $82(50.31)$ & $74(52.86)$ & & \\
\hline Fibroid location & $(n=163)$ & $(\mathrm{n}=140)$ & 0.158 & 0.722 \\
\hline Anterior wall/Posterior wall & $100(61.35)$ & $89(63.57)$ & & \\
\hline Uterine fundus & $63(38.65)$ & $51(36.43)$ & & \\
\hline Fibroid target skin distance $(\mathrm{cm})$ & $(n=163)$ & $(\mathrm{n}=140)$ & 0.198 & 0.729 \\
\hline$<7$ & $88(53.99)$ & $72(51.43)$ & & \\
\hline$\geq 7$ & $75(46.01)$ & $68(48.57)$ & & \\
\hline Fibroid type & $(n=163)$ & $(n=140)$ & 0.073 & 0.795 \\
\hline Muscle wall & $121(74.23)$ & $102(72.86)$ & & \\
\hline Non-muscle wall & $42(25.77)$ & $38(27.14)$ & & \\
\hline
\end{tabular}

technique in the treatment of uterine fibroid is increasing and requirements are also gradually increasing.

High intensity focused ultrasound (HIFU) technology is new for the treatment of tumors with non-invasiveness (8). The main principle is to use ultrasonic waves with characteristics such as tissue penetrating and focusability to concentrate the low-intensity ultrasonic waves on the lesions in the body, so that the focus area rapidly warms up to $60-100^{\circ} \mathrm{C}$, resulting in coagulation necrosis of the target tissues, but at the same time, it does not damage the tissues outside the target area. Detection of pathology and related enzymes in the tissues around the target area is strong evidence, and no significant changes have been found $(9,10)$. The advantage of HIFU is that it has the same effect as myomectomy and can cause necrosis of fibroid tissues, but it can avoid the damage of ultrasonic waves to normal tissues, so as to achieve the effect of minimally invasive treatment. This has been confirmed by clinical manifestations of patients and imaging $(11,12)$. At the same time, HIFU has played a safe and effective role in patients with a willingness to have pregnancy, not only to allow uterine cavity a good recovery, but also to retain pregnancy ability (13).

This study investigated the effect of HIFU uterine fibroid ablation on the endometrial receptivity and sex hormone level in uterine fibroid patients and the analysis of influencing factors for treatment rate, to provide the decision-making basis for selection of HIFU ablation in the treatment of uterine fibroid indications, and optimization and standardization of treatment schemes.

The study was approved by the Ethics Committee of Jining Maternity and Child Care Hospital (Jining, China). Patients who participated in this research had complete clinical data. The signed informed consents were obtained from the patients or the guardians.

\section{Materials and methods}

General information. A retrospective analysis of 266 uterine fibroid patients, who meet the symptoms of uterine fibroid, confirmed clinically and by imaging in the Jining Maternity and Child Care Hospital from October 2013 to October 2016, was performed. The observation group was treated with HIFU ablation, a total of 143 cases, 163 fibroids, with an average age of $36.25 \pm 7.13$ years. The control group was treated with myomectomy, a total of 123 cases, 140 fibroids, with an average age of $35.75 \pm 6.42$ years. There was no significant difference in general information between the two groups $(\mathrm{P}>0.05)$. All patients in pregnancy and lactation, suffering from other gynecological diseases, heart disease, malignant tumors and coagulation dysfunction were excluded, and patients who had not taken hormone drugs within 6 months were included (Table I).

Treatment methods. JC-200 type HIFU (Chongqing Haifu Medical Technology Co., Ltd., Chongqing, China) was used for ablation therapy within one week after menstruation in observation group. The treatment diameter was $195 \mathrm{~mm}$, and the treatment power was 160-420 W. Ultrasound scanning located the extent of fibroid lesions, captured dynamic images and located planar areas. Ultrasound probes were used to determine the number, size and location of fibroids, and lesion target areas were differentiated into different treatment levels. Patients were placed in a supine position and a dot-linesurface ablation treatment was performed through the focus area according to the treatment plan. At the same time, routine ultrasound examination, ultrasound contrast and MRI examination were performed at 1 month before and within 6 months after treatment to determine the therapeutic effect. 
Table II. Modified RECIST criteria for evaluating the curative effect of cancer therapy.

Ablation rate

Evaluation of effect

Ablation rate $<50 \%$

$>0$ ablation rate $\leq 50 \%$

Ablation rate $=0$

Table III. Comparison of preoperative and postoperative PI and RI between the two groups.

\begin{tabular}{|c|c|c|c|c|c|}
\hline \multirow[b]{2}{*}{ Indicators } & \multirow[b]{2}{*}{ Time } & \multicolumn{2}{|c|}{ Groups } & \multirow[b]{2}{*}{$\mathrm{t}$ value } & \multirow[b]{2}{*}{ P-value } \\
\hline & & $\begin{array}{l}\text { Observation } \\
\qquad(\mathrm{n}=143)\end{array}$ & $\begin{array}{l}\text { Control } \\
(n=123)\end{array}$ & & \\
\hline \multirow[t]{4}{*}{ PI } & Preoperative & $1.81 \pm 0.13$ & $1.83 \pm 0.15$ & 1.165 & 0.245 \\
\hline & Postoperative & $1.83 \pm 0.16$ & $1.86 \pm 0.17$ & 1.919 & 0.056 \\
\hline & t value & 1.160 & 1.957 & & \\
\hline & P-value & 0.247 & 0.052 & & \\
\hline \multirow[t]{4}{*}{ RI } & Preoperative & $0.92 \pm 0.14$ & $0.89 \pm 0.12$ & 1.860 & 0.064 \\
\hline & Postoperative & $0.94 \pm 0.12$ & $0.91 \pm 0.13$ & 1.956 & 0.051 \\
\hline & $\mathrm{t}$ value & 1.297 & 1.254 & & \\
\hline & P-value & 0.196 & 0.211 & & \\
\hline
\end{tabular}

PI, pulsatility index; RI, resistance index.

The control group was treated with myomectomy, including transabdominal, laparoscope and transvaginal myomectomy.

Observation indicators. The PI and RI of the uterine arterial blood flow were measured during the luteal phase of menstruation by transvaginal ultrasonography at 1 month before and within 6 months after operation. At the same time, the sex hormone level was measured, and $4 \mathrm{ml}$ of fasting cubital venous blood were extracted. Serum LH, FSH and $\mathrm{E}_{2}$ were detected by chemical immunofluorescence.

Evaluation of curative effect. The ablation rate of fibroid was calculated according to the following formula and evaluation criteria, and the curative effect was evaluated (14) (Table II):

Preoperative uterine fibroid volume $=1 / 6 \mathrm{x} \pi \mathrm{x}$ long diameter $\mathrm{x}$ wide diameter $\mathrm{x}$ thick diameter.

Ablation rate $=$ fibroid volume after ablation/preoperative uterine fibroid volume $\mathrm{x} 100 \%$.

Statistical analysis. SPSS20.0 statistical software (IBM Corp., Armonk, NY, USA) was used for data analysis. Chi-square test was used for count data, t-test for measurement data, paired $\mathrm{t}$-test for comparison between before and after treatment in the group, and logistic, univariate and multivariate regression analyses for the influencing factors for HIFU treatment rate. ANOVA was used for comparison beween multiple groups with LSD test. $\mathrm{P}<0.05$ was considered to indicate a statistically significant difference.

\section{Results}

Comparison of preoperative and postoperative PI and RI between the two groups. There was no significant difference in preoperative and postoperative PI and RI between the two groups ( $\mathrm{P}>0.05)$; no significant difference between preoperative PI and postoperative PI in the same group ( $\mathrm{P}>0.05)$, neither RI (P>0.05) (Fig. 1; Table III).

Comparison of preoperative and postoperative sex hormone level between the two groups. There was no significant difference in preoperative and postoperative $\mathrm{LH}, \mathrm{FSH}$ and $\mathrm{E}_{2}$ between the two groups $(\mathrm{P}>0.05)$; no significant difference between preoperative $\mathrm{LH}$ and postoperative $\mathrm{LH}$ in the same group (P>0.05), neither FSH or $\mathrm{E}_{2}(\mathrm{P}>0.05)$ (Fig. 2; Table IV).

Relationship between HIFU treatment rate and clinical pathology of uterine fibroid. There was no significant
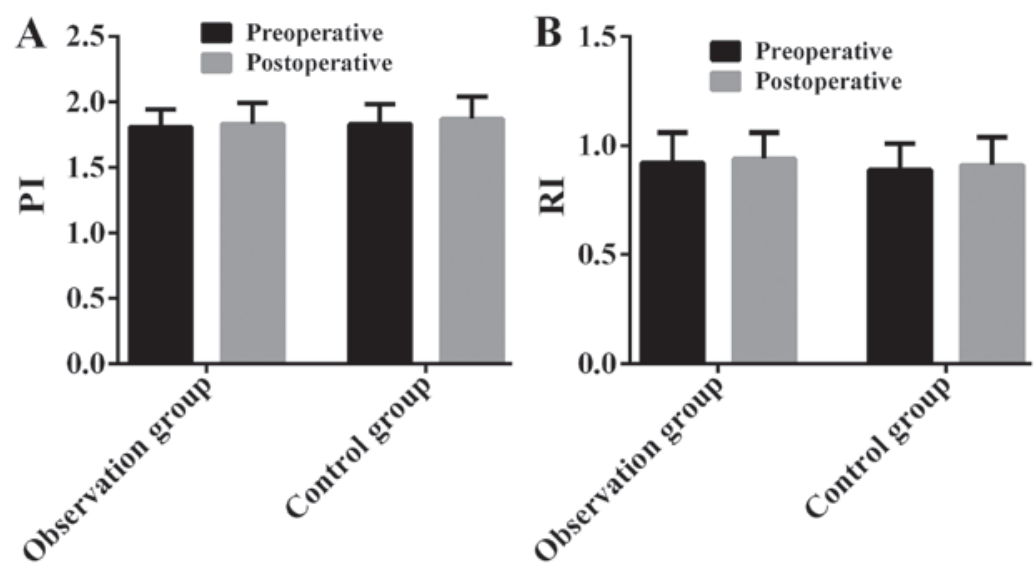

Figure 1. Comparison of preoperative and postoperative PI and RI between the two groups. Results of chemical immunofluorescence showed that: (A) There was no significant difference concerning preoperative PI and postoperative PI between the two groups (P>0.05); no significant difference was observed between preoperative PI and postoperative PI in the same group (P>0.05). (B) There was no significant difference concerning preoperative RI and postoperative RI between the two groups ( $\mathrm{P}>0.05)$; no significant difference was observed between preoperative RI and postoperative RI in the same group ( $>0.05)$. $\mathrm{PI}$, pulsatility index; RI, resistance index. 


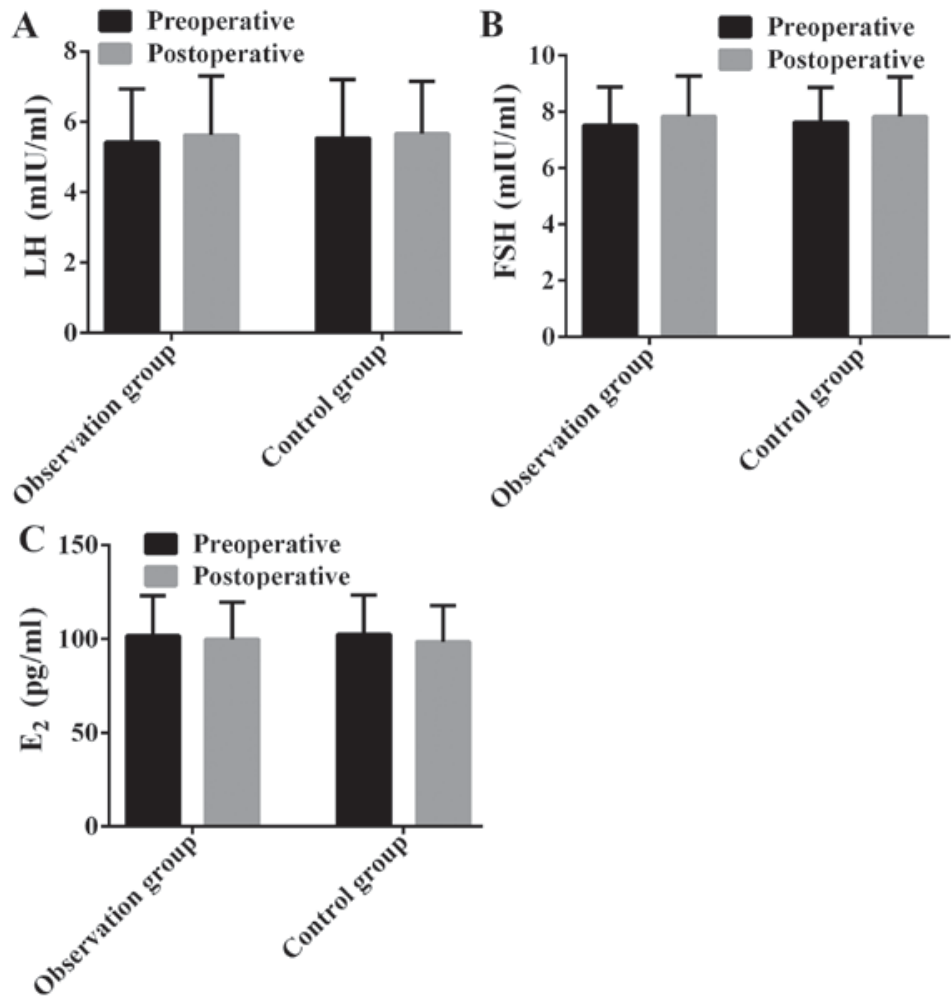

Figure 2. Comparison of preoperative and postoperative sex hormone level between the two groups. Results of chemical immunofluorescence showed that: (A) There was no significant difference in preoperative LH and postoperative LH between the two groups ( $>>0.05)$; no significant difference was observed between preoperative $\mathrm{LH}$ and postoperative $\mathrm{LH}$ in the same group $(\mathrm{P}>0.05)$. (B) There was no significant difference in preoperative FSH and postoperative FSH between the two groups $(\mathrm{P}>0.05)$; no significant difference was observed between preoperative FSH and postoperative FSH in the same group $(\mathrm{P}>0.05)$. (C) There was no significant difference in preoperative $\mathrm{E}_{2}$ and postoperative $\mathrm{E}_{2}$ between the two groups $(\mathrm{P}>0.05)$; no significant difference was observed between preoperative $\mathrm{E}_{2}$ and postoperative $\mathrm{E}_{2}$ in the same group ( $\left.\mathrm{P}>0.05\right)$. $\mathrm{LH}$, luteinizing hormone; $\mathrm{FSH}$, follicle stimulating hormone; $\mathrm{E}_{2}$, estradiol.

Table IV. Comparison of preoperative and postoperative sex hormone level between the two groups.

\begin{tabular}{|c|c|c|c|c|c|}
\hline \multirow[b]{2}{*}{ Items } & \multirow[b]{2}{*}{ Time } & \multicolumn{2}{|c|}{ Groups } & \multirow[b]{2}{*}{$\mathrm{t}$ value } & \multirow[b]{2}{*}{ P-value } \\
\hline & & Observation $(n=143)$ & Control (n=123) & & \\
\hline \multirow[t]{4}{*}{ LH (mIU/ml) } & Preoperative & $5.41 \pm 1.52$ & $5.53 \pm 1.67$ & 0.613 & 0.540 \\
\hline & Postoperative & $5.62 \pm 1.68$ & $5.66 \pm 1.48$ & 0.205 & 0.838 \\
\hline & t value & 1.108 & 0.646 & & \\
\hline & P-value & 0.269 & 0.519 & & \\
\hline \multirow{4}{*}{ FSH (mIU/ml) } & Preoperative & $7.51 \pm 1.36$ & $7.62 \pm 1.32$ & 0.667 & 0.506 \\
\hline & Postoperative & $7.83 \pm 1.45$ & $7.82 \pm 1.42$ & 0.057 & 0.955 \\
\hline & $\mathrm{t}$ value & 1.925 & 1.177 & & \\
\hline & P-value & 0.055 & 0.241 & & \\
\hline \multirow[t]{4}{*}{$\mathrm{E}_{2}(\mathrm{pg} / \mathrm{ml})$} & Preoperative & $101.56 \pm 21.43$ & $102.34 \pm 20.95$ & 0.299 & 0.765 \\
\hline & Postoperative & $99.82 \pm 19.64$ & $98.42 \pm 19.13$ & 0.587 & 0.558 \\
\hline & $\mathrm{t}$ value & 0.716 & 1.532 & & \\
\hline & $\mathrm{P}$-value & 0.475 & 0.127 & & \\
\hline
\end{tabular}

LH, luteinizing hormone; FSH, follicle stimulating hormone; $\mathrm{E}_{2}$, estradiol.

association between HIFU treatment rate and age, tumor diameter, tumor volume, fibroid type and ultrasonic echo intensity $(\mathrm{P}>0.05)$; but an association between HIFU treatment rate and fibroid location, fibroid target skin distance and ultrasound contrast intensity $(\mathrm{P}<0.05)$ (Table V).
Analysis of influencing factors for HIFU treatment rate. Statistically different factors in Table V were used as independent variables for univariate/multivariate regression analysis. Results of univariate analysis showed that HIFU treatment rate was associated with fibroid location, fibroid target skin 
Table V. Relationship between HIFU treatment rate and clinical pathology of uterine fibroid (n, \%).

\begin{tabular}{|c|c|c|c|c|}
\hline Factors & $\begin{array}{l}\text { Effective } \\
(n=123)\end{array}$ & $\begin{array}{c}\text { Marked } \\
\text { effective } \\
(n=40)\end{array}$ & $\chi^{2}$ & P-value \\
\hline Age (years) & & & 0.623 & 0.469 \\
\hline$<35$ & $58(47.15)$ & $16(40.00)$ & & \\
\hline$\geq 35$ & $65(52.85)$ & $24(60.00)$ & & \\
\hline Tumor diameter $(\mathrm{cm})$ & & & 0.918 & 0.367 \\
\hline$<4$ & $63(51.22)$ & $17(42.50)$ & & \\
\hline$\geq 4$ & $60(48.78)$ & $23(57.50)$ & & \\
\hline Tumor volume $\left(\mathrm{cm}^{3}\right)$ & & & 1.097 & 0.363 \\
\hline$<54$ & $64(52.03)$ & $17(42.50)$ & & \\
\hline$\geq 54$ & $59(47.97)$ & $23(57.50)$ & & \\
\hline Fibroid location & & & 4.478 & 0.036 \\
\hline Anterior wall/ & $76(61.79)$ & $32(80.00)$ & & \\
\hline $\begin{array}{l}\text { Posterior wall } \\
\text { Uterine fundus }\end{array}$ & $47(38.21)$ & $8(20.00)$ & & \\
\hline $\begin{array}{l}\text { Fibroid target } \\
\text { skin distance }(\mathrm{cm})\end{array}$ & & & 8.223 & 0.006 \\
\hline$<7$ & $69(56.10)$ & $12(30.00)$ & & \\
\hline$\geq 7$ & $54(43.90)$ & $28(70.00)$ & & \\
\hline Fibroid type & & & 0.505 & 0.553 \\
\hline Muscle wall & $85(69.11)$ & $30(75.00)$ & & \\
\hline Non-muscle wall & $38(30.89)$ & $10(25.00)$ & & \\
\hline $\begin{array}{l}\text { Ultrasound contrast } \\
\text { intensity }\end{array}$ & & & 14.466 & 0.001 \\
\hline Low intensity & $24(19.51)$ & $19(47.50)$ & & \\
\hline Equal intensity & $41(33.33)$ & $13(32.50)$ & & \\
\hline High intensity & $58(47.15)$ & $8(20.00)$ & & \\
\hline $\begin{array}{l}\text { Ultrasonic echo } \\
\text { intensity }\end{array}$ & & & 0.180 & 0.914 \\
\hline Low echo & $54(43.90)$ & $18(45.00)$ & & \\
\hline Equal echo & $47(38.21)$ & $16(40.00)$ & & \\
\hline High echo & $22(17.89)$ & $6(15.00)$ & & \\
\hline
\end{tabular}

distance and ultrasound contrast intensity $(\mathrm{P}<0.05)$, but it was not associated with age, tumor diameter, tumor volume, fibroid type and ultrasonic echo intensity $(\mathrm{P}>0.05)$. Results of multivariate analysis showed that fibroid location and ultrasound contrast intensity were independent influencing factors for HIFU treatment rate, and the difference was statistically significant $(\mathrm{P}<0.05)$ (Tables VI and VII).

\section{Discussion}

Uterine fibroid is a gynecological disease with a high incidence, prevalent in menopausal women and lacking typical clinical symptoms. Only a small proportion of patients of childbearing age will consult a doctor because of increased menstrual blood volume (15). For the treatment of uterine fibroid, myomectomy, interventional therapy and drug therapy may not be accepted by the majority of patients, due to risks such as large wound area, long recovery period, metabolic disorder, decreased immune function, decreased
Table VI. Univariate analysis of influencing factors for HIFU treatment rate.

\begin{tabular}{lccc}
\hline Items & OR & $95 \%$ CI & P-value \\
\hline $\begin{array}{l}\text { Fibroid location } \\
\begin{array}{l}\text { Fibroid target } \\
\text { skin distance (cm) }\end{array}\end{array}$ & 6.453 & $3.562-10.245$ & 0.026 \\
$\begin{array}{l}\text { Ultrasound contrast } \\
\text { intensity }\end{array}$ & 7.965 & $1.754-9.523$ & 0.019 \\
Age (years) & 5.168 & $3.468-16.255$ & 0.216 \\
Tumor diameter $\left(\mathrm{cm}^{3}\right)$ & 8.629 & $4.256-12.856$ & 0.082 \\
Tumor volume $\left(\mathrm{cm}^{3}\right)$ & 8.236 & $5.826-16.544$ & 0.071 \\
Fibroid type & 6.102 & $3.719-18.408$ & 0.104 \\
Ultrasonic echo intensity & 7.338 & $2.913-15.742$ & 0.069 \\
\hline
\end{tabular}

HIFU, high intensity focused ultrasound.

Table VII. Multivariate analysis of influencing factors for HIFU treatment rate.

\begin{tabular}{lccc}
\hline Items & OR & $95 \% \mathrm{CI}$ & P-value \\
\hline Fibroid location & 7.216 & $3.456-9.541$ & 0.032 \\
$\begin{array}{l}\text { Ultrasound contrast } \\
\text { intensity }\end{array}$ & 8.015 & $3.568-12.482$ & 0.015 \\
\end{tabular}

HIFU, high intensity focused ultrasound.

sexual desire, and easy to reduce the ovarian function (16-18). Therefore, in clinical practice, the treatment of retaining the uterus has become the norm.

Results of this study showed that there was no significant difference in preoperative and postoperative PI and RI between the two groups ( $\mathrm{P}>0.05)$; no significant difference between preoperative PI and postoperative PI in the two groups $(\mathrm{P}>0.05)$, neither RI $(\mathrm{P}>0.05)$. It suggests that HIFU treatment has no effect on endometrial receptivity and it is safe and effective. There was no significant difference in preoperative and postoperative $\mathrm{LH}, \mathrm{FSH}$ and $\mathrm{E}_{2}$ between the two groups ( $\mathrm{P}>0.05)$; no significant difference between preoperative LH and postoperative $\mathrm{LH}$ in the same group $(\mathrm{P}>0.05)$, or FSH and $\mathrm{E}_{2}(\mathrm{P}>0.05)$. The study results of $\mathrm{Fu}$ et al (19) are different from ours. HIFU was effective in the treatment of uterine fibroid and can significantly improve its clinical symptoms. Serum LH level after treatment was significantly higher than that before treatment $(\mathrm{P}<0.05)$, and serum $\mathrm{E}_{2}$ and FSH levels after treatment were significantly lower than those before treatment $(\mathrm{P}<0.05)$. It may be due to the large difference in the sample size, and the control group set up in this study was treated with myomectomy. However, study of Yang et al only compared HIFU between before and after treatment (16). Study of Rueff et al (20) showed that there was no significant difference in serum FSH level between before and after treatment with HIFU in uterine fibroid patients. This is basically consistent with the results of this study that both LH and FSH slightly improved. The observation group was grouped through 
imaging examination according to the ablation rate after treatment. Results of logistic univariate analysis showed that HIFU treatment rate was associated with fibroid location, fibroid target skin distance and ultrasound contrast intensity $(\mathrm{P}<0.05)$, but it was not associated with age, tumor diameter, tumor volume, fibroid type and ultrasonic echo intensity $(\mathrm{P}>0.05)$. Results of multivariate analysis showed that fibroid location and ultrasound contrast intensity were independent influencing factors for HIFU treatment rate, and the difference was statistically significant $(\mathrm{P}<0.05)$. This is basically consistent with the findings of Donnez et al (21), which showed that the treatment rate was related to fibroid location. According to reports in the literature (22), the fibroid is located on the anterior wall and the anterior uterine fundus can be better focused on in the lesion, due to the proximity of the bladder and the short target skin distance; at the same time, it is far away from the intestinal tract, sacral bone and peripheral nerves. Therefore, the safety and the tolerance of patients with anterior wall and anterior uterine fundus are better, and HIFU treatment rate is also higher. The study results of Chen et al (23) showed that the higher the ultrasound contrast intensity was, the richer the perfusion of uterine fibroid was, resulting in a lower HIFU treatment rate. The reason may be that after the absorption of ultrasound energy, the blood flow will leave the focus area of the lesion as the circulation moves, leading to a decrease in heat accumulation that is the key of the treatment of uterine fibroid with HIFU (24).

In conclusion, treatment of uterine fibroid with HIFU has no effect on the patient's endometrial receptivity and sex hormone level. Fibroid location and ultrasound contrast intensity are independent risk factors for HIFU treatment. This study provides guidance for the clinical optimization of treatment methods and is more conducive to the promotion of HIFU ablation therapy.

\section{Acknowledgements}

Not applicable.

\section{Funding}

No funding was received.

\section{Availability of data and materials}

The datasets used and/or analyzed during the present study are available from the corresponding author on reasonable request.

\section{Authors' contributions}

YC and BG conceived and designed the study. YD, XG and DS collected and analyzed the data. YC, YD and BG wrote the manuscript and revised it critically. CX was responsible for observation indicators analysis. All authors read and approved the final manuscript.

\section{Ethics approval and consent to participate}

The study was approved by the Ethics Committee of Jining Maternity and Child Care Hospital (Jining, China). Patients who participated in this research had complete clinical data. The signed informed consents were obtained from the patients or the guardians.

\section{Patient consent for publication}

Not applicable.

\section{Competing interests}

The authors declare that they have no competing interests.

\section{References}

1. Rizzello A, Franck J, Pellegrino M, De Nuccio F, Simeone P, Fiore G, Di Tommaso S, Malvasi A, Tinelli A, Fournier I, et al: A Proteomic Analysis of Human Uterine Myoma. Curr Protein Pept Sci 18: 167-174, 2017.

2. Nelson AL and Massoudi N: New developments in intrauterine device use: Focus on the US. Open Access J Contracept 7: 127-141, 2016.

3. Donnez J and Dolmans MM: Uterine fibroid management: From the present to the future. Hum Reprod Update 22: 665-686, 2016.

4. Chiaffarino F, Cipriani S, Ricci E, La Vecchia C, Chiantera V, Bulfoni A and Parazzini F: Alcohol consumption and risk of uterine myoma: A systematic review and meta analysis. PLoS One 12: e0188355, 2017

5. Giudice LC: Potential biochemical markers of uterine receptivity. Hum Reprod 14 (Suppl 2): 3-16, 1999.

6. Hoozemans DA, Schats R, Lambalk NB, Homburg R and Hompes PG: Serial uterine artery Doppler velocity parameters and human uterine receptivity in IVF/ICSI cycles. Ultrasound Obstet Gynecol 31: 432-438, 2008.

7. Khan AT, Shehmar M and Gupta JK: Uterine fibroids: Current perspectives. Int J Womens Health 6: 95-114, 2014.

8. Guo Q, Zhao W, Xu F, Zhang S and Chen P: Validity of high intensive focused ultrasound in the treatment of uterus myoma and adenomyoma in Hebei Province: A report of 166 cases. Zhonghua Yi Xue Za Zhi 95: 693-696, 2015 (In Chinese).

9. Pron G: Magnetic resonance-guided high-intensity focused ultrasound (MRgHIFU) treatment of symptomatic uterine fibroids: An evidence-based analysis. Ont Health Technol Assess Ser 15: 1-86, 2015.

10. Daher S, Massarwa M, Benson AA and Khoury T: Current and future treatment of hepatocellular carcinoma: An updated comprehensive review. J Clin Transl Hepatol 6: 69-78, 2018.

11. Trefoux Bourdet A, Luton D and Koskas M: Clinical utility of ulipristal acetate for the treatment of uterine fibroids: Current evidence. Int J Womens Health 7: 321-330, 2015.

12. Yin H, Lo JH, Kim JY, Marsh EE, Kim JJ, Ghosh AK, Bulun S and Chakravarti D: Expression profiling of nuclear receptors identifies key roles of NR4A subfamily in uterine fibroids. Mol Endocrinol 27: 726-740, 2013.

13. Lumsden MA: Modern management of fibroids. Obstetrics, Gynaecol Reprod Med 20: 82-86, 2010.

14. Ghobrial FEI, Eldin MS, Razek AAKA, Atwan NI and Shamaa SSA: Computed tomography assessment of hepatic metastases of breast cancer with revised response evaluation criteria in solid tumors (RECIST) criteria (Version 1.1): Inter-observer agreement. Pol J Radiol 82: 593-597, 2017.

15. Cohen LS and Valle RF: Role of vaginal sonography and hysterosonography in the endoscopic treatment of uterine myomas. Fertil Steril 73: 197-204, 2000.

16. Yang R, Xu T, Fu Y, Cui S, Yang S and Cui M: Leiomyomatosis peritonealis disseminata associated with endometriosis: A case report and review of the literature. Oncol Lett 9: 717-720, 2015.

17. Szkodziak P, Szkodziak F, Trzeciak K and Czuczwar P: Minimally invasive procedures in the management of uterine fibroids. Przegl Menopauz 16: 122-125, 2017.

18. Zhou J and Qu F: Treating gynaecological disorders with traditional Chinese medicine: A review. Afr J Tradit Complement Altern Med 6: 494-517, 2009.

19. Fu X, Huang F, Chen Y, Deng Y and Wang Z: Application of dexmedetomidine-remifentanil in high-intensity ultrasound ablation of uterine fibroids: A randomised study. BJOG 124 (Suppl 3): 23-29, 2017 
20. Rueff LE and Raman SS: Clinical and technical aspects of MR-guided high intensity focused ultrasound for treatment of symptomatic uterine fibroids. Semin Intervent Radiol 30: 347-353, 2013

21. Donnez J, Arriagada P, Donnez O and Dolmans MM: Emerging treatment options for uterine fibroids. Expert Opin Emerg Drugs 23: 17-23, 2018.

22. Long L, Chen J, Xiong Y, Zou M, Deng Y, Chen L and Wang Z: Efficacy of high-intensity focused ultrasound ablation for adenomyosis therapy and sexual life quality. Int J Clin Exp Med 8: 11701-11707, 2015.
23. Chen L, ter Haar G, Hill CR, Dworkin M, Carnochan P, Young H and Bensted JP: Effect of blood perfusion on the ablation of liver parenchyma with high-intensity focused ultrasound. Phys Med Biol 38: 1661-1673, 1993.

24. Elhelf IAS, Albahar H, Shah U, Oto A, Cressman E and Almekkawy M: High intensity focused ultrasound: The fundamentals, clinical applications and research trends. Diagn Interv Imaging 99: 349-359, 2018.

c) (i) (2) This work is licensed under a Creative Commons c) Attribution-NonCommercial-NoDerivatives 4.0 International (CC BY-NC-ND 4.0) License. 